\title{
Microphysical effects of Saharan dusts on an orogenic thunderstorm
}

\section{T. Hashino}

Department of Atmospheric and Ocenic Sciences, University of Wisconsin - Madison, Madison, WI, USA

Received: 15 January 2008 - Revised: 12 April 2008 - Accepted: 23 May 2008 - Published: 20 June 2008

\begin{abstract}
This study investigates the microphysical sensitivity of an orogenic thunderstorm during Genoa 1992 flood event to the concentration and solubility of nucleating aerosols. Idealized 2-D simulations with a new microphysical scheme and a cloud resolving model showed the solubility of CCN can be as important as their concentration. High solubility cases of CCN led to less accumulation of precipitation on the ground and more fraction of the accumulation produced by heavy precipitation than lower solubility cases. The response of vertical motion to the solubility was different for cases with and without dust layer. The preliminary results show that the ice nucleation processes affected by solubility and dust layer may be detected by remote sensing technology.
\end{abstract}

\section{Introduction}

Saharan dusts are usually transported into the Mediterranean by southerly wind associated with cyclones in spring and summer (e.g., Barkan et al., 2005). The particles modulate energy budget of the earth by absorption and scattering of solar and thermal radiation. Another aspect of Saharan dusts is the cloud microphysical impact, and therefore potential impact on water resources and hydrological cycle. Dust particles are known as good ice nuclei (IN). The dusts can be coated with soluble material through adsorption of soluble gasses and collisions with soluble aerosols. Then, the mixed particles can serve as cloud condensation nuclei (CCN). Khain et al. (2005) and Van Den Heever et al. (2005) came to the conclusion that higher concentration of CCN lead to larger latent heat release, therefore more vigorous updrafts, and more sublimation and evaporation lead to decrease in precipitation efficiency of a single convective cloud.

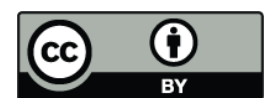

Correspondence to: T. Hashino (hashino@wisc.edu)
A moist boundary layer capped with elevated mixed layer came into place over Genoa, Italy on 27th September 1992, and the convection triggered over the relatively low topography north of Genoa produced deadly flash flood (Tripoli et al., 2001). Even though there is no evidence for this particular case, it is possible that some of the elevated mixed layers advected from Africa contain Saharan dusts. This study investigates the microphysical effects of a dust layer with insoluble IN and effects of solubility of CCN on the orogenic thunderstorm by numerical simulation. A newly developed numerical model for microphysical processes, Advanced Microphysical Prediction System (AMPS, Hashino and Tripoli, 2007) is used within a cloud resolving model, University of Wisconsin Nonhydrostatic Modeling System (UW-NMS, Tripoli, 1992).

\section{Experiment design}

Idealized 2-D simulations of the orogenic thunderstorm are implemented from a sounding obtained from a 3-D simulation of the Genoa flood event with UW-NMS. Two categories of aerosols are predicted. IN category consists of insoluble dust particles, whereas $\mathrm{CCN}$ category consists of internally mixed particles (mixture of dusts and sea salts). IN were predicted in the UW-NMS to regulate contact freezing nucleation and deposition-condensation nucleation process, while $\mathrm{CCN}$ to control cloud droplets activation, and in turn freezing nucleation processes of cloud droplets. Four cases were designed by changing solubility of CCN and number concentration of IN. The cases DI and DS have a dust layer as shown in Fig. 1 with soluble mass fraction to total aerosol mass of CCN, 0.01 and 0.99 , respectively. The cases CI and CS have no dust layer but with the same soluble mass fractions as DI and DS, respectively. This sensitivity experiments chose the extreme solubility cases to see the possible maximum impact. Significant dust events over Asia are known to produce dusts with soluble fraction as low as 0.03 (Wang et al., 2005). In general, maritime air contains aerosols with the

Published by Copernicus Publications on behalf of the European Geosciences Union. 


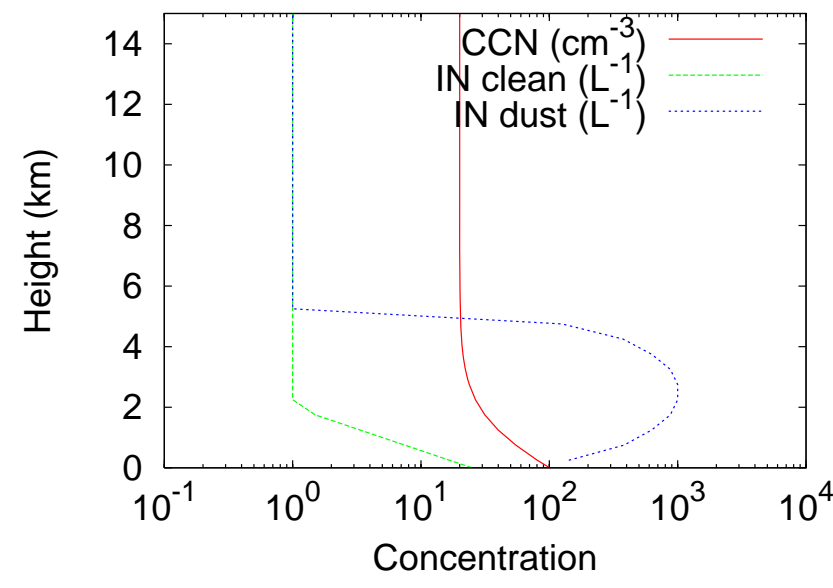

Fig. 1. Initial vertical distribution of number concentration of $\mathrm{CCN}$ and IN for clean and dust cases.

Table 1. Comparison of precipitation on the ground $(175<\mathrm{y}<350 \mathrm{~km})$ for nine hours simulation.

\begin{tabular}{lllll}
\hline & $\begin{array}{l}\text { Ave. accum. } \\
\text { prec. }(\mathrm{mm})\end{array}$ & $\begin{array}{l}\text { Ave. prec. } \\
\text { rate } \\
\left(\mathrm{mm} \mathrm{hr}^{-1}\right)\end{array}$ & $\begin{array}{l}\text { Ave. prec. } \\
\text { rate } \\
\left(>100 \mathrm{~mm} \mathrm{hr}^{-1}\right)\end{array}$ & $\begin{array}{l}\text { Fraction of } \\
\text { heavy prec. } \\
\text { to total } \\
\left(>100 \mathrm{~mm} \mathrm{hr}^{-1}\right)\end{array}$ \\
\hline DI & 32.1 & 21 & 140 & 0.11 \\
DS & 27.1 & 20 & 130 & 0.19 \\
CI & 30.7 & 19 & 131 & 0.084 \\
CS & 28.5 & 25 & 141 & 0.33 \\
\hline
\end{tabular}

fraction from 0.8 to 1.0 (Pruppacher and Klett, 1997). Thus, the tested extreme solubility seems to be realistic.

\section{Results}

Spectral Habit Ice Prediction System (SHIPS), which is one component of AMPS, was developed to conserve growth history of ice particles and predict the ice particle properties in Eulerian dynamics models. It provides information such as crystal habits, particle types, densities, and maximum dimensions of ice particles useful for forward radiative transfer calculation. Figure 2 shows the spatial distribution of diagnosed ice crystal habits at three hours of simulation from DI along the 2-D topography over Genoa. Planar and columnar crystals are dominant in the updraft cores $(4<z<10 \mathrm{~km}$ and $210<y<250 \mathrm{~km}$ ), while irregular polycrystals prevails in the anvil.

Some measures of precipitation on the ground are shown in Table 1. DI produced the highest average accumulated precipitation on the ground over the horizontal distance, $175<y<350 \mathrm{~km}$, and nine hours. Increasing the solubility of CCN caused decrease in the accumulation of by $16 \%$ (7.1\%) for dust layer cases (clean cases), and the accumu- lation turned out to be less sensitive to the presence of the dust layer than to the CCN's solubility.

According to Kohler curve, higher solubility of $\mathrm{CCN}$ leads to activation of smaller $\mathrm{CCN}$ for a given supersaturation. As a result the concentrations of activated CCN for DS and CS were about ten times higher $\left(100 \mathrm{~cm}^{-3}\right)$ and the droplets were smaller than DI and CI. The size of supercooled droplets then affected the immersion and homogeneous freezing processes and riming process. Average concentration tendencies by the freezing processes were more active for DI than for DS, and the nucleated particles for DI were larger than DS. The riming process of DI was slightly more active than DS on horizontal average. The size difference of frozen droplets is speculated to be one of the reasons for the difference in accumulation of precipitation on the ground.

CS has the largest average precipitation rate among the simulations, and $33 \%$ of the total accumulation was produced by the heavy precipitation. The clean cases show more sensitivity of the solubility on the precipitation rate. The high solubility cases had more fraction of accumulation produced by heavy precipitation rate. It is hypothesized that small cloud droplets can be suspended in the strong updraft for DS and CS, so that the nucleated ice particles can collect more mass of the cloud droplets as they fall.

The upward vertical velocity in the updraft where the velocity is greater than $1 \mathrm{~m} \mathrm{~s}^{-1}$ was averaged over $200<y<300 \mathrm{~km}$ (Fig. 3). It can be seen that the case of high solubility with dust layer (DS) exhibits the strongest updraft, while CS has the weakest. The response of the vertical motion to the solubility of $\mathrm{CCN}$ appears to be opposite for dust layer cases and clean cases. CI and CS simulated updraft cores at higher altitude than DI and DS. Detail thermodynamical analysis has to be done to find out the cause.

Total projected area of ice particles was calculated and averaged over $150<y<350 \mathrm{~km}$ (Fig. 4). The variable is closely related to extinction coefficient in visible wavelength. The region of high projected area at $10<z<12 \mathrm{~km}$ for DS and CS is associated with higher concentration of small ice particles than DI and CI. The high concentration is most likely caused by smaller sedimentation of ice particles in DS and $\mathrm{CS}$ than DI and CI. The active deposition-condensation nucleation process at $5<z<8 \mathrm{~km}$ for DI and DS corresponds to the high projected area at the level.

\section{Conclusions}

The precipitation process of an orogenic thunderstorm has sensitivity to solubility of CCN (dusts coated with soluble material) as well as dust layer. The precipitation accumulation turned out to be less sensitive to the dust layer than the solubility. The increase in $\mathrm{CCN}$ solubility resulted in the reduction of precipitation by $16 \%$ between dust layer cases. The dust layer cases showed increase in the vertical motion 
(a) Plates $\left(\log 10\left(L^{-1}\right)\right)$

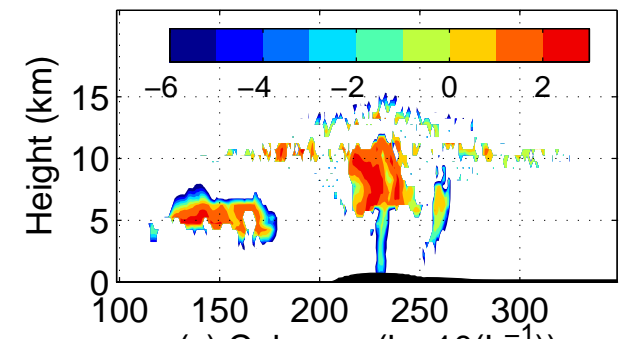

(c) Columns $\left(\log 10\left(\mathrm{~L}^{-1}\right)\right)$

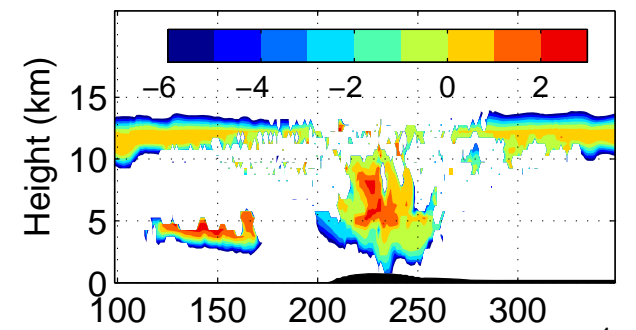

(e) Planar polycrystals $\left(\log 10\left(\mathrm{~L}^{-1}\right)\right)$

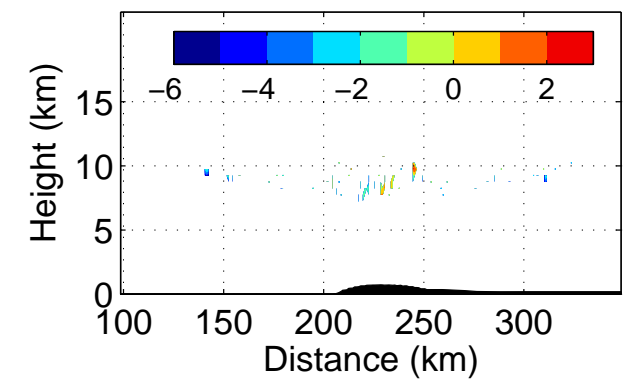

(b) Dendrites $\left(\log 10\left(\mathrm{~L}^{-1}\right)\right)$

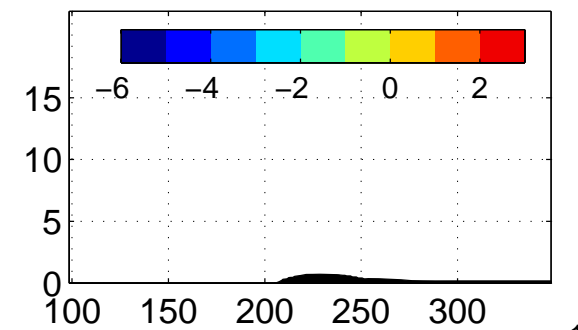

(d) Columnar polycrystals $\left(\log 10\left(\mathrm{~L}^{-1}\right)\right)$

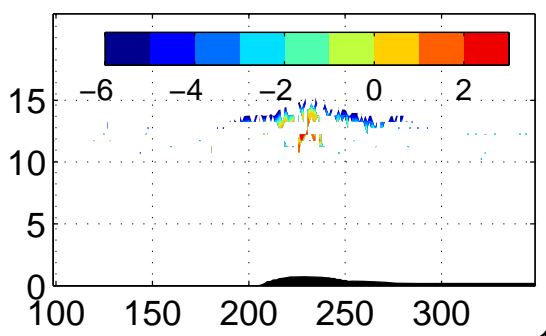

(f) Irregular polycrystals $\left(\log 10\left(\mathrm{~L}^{-1}\right)\right)$

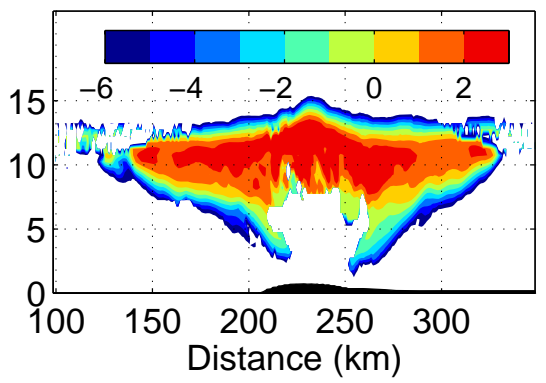

Fig. 2. Number concentration of ice crystal habits at three hours of simulation for DI. The black fill indicates the topography over Genoa area, and the left of the topography is Mediterranean Sea.

(a) DI

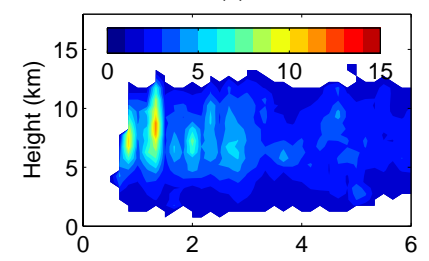

(c) $\mathrm{Cl}$

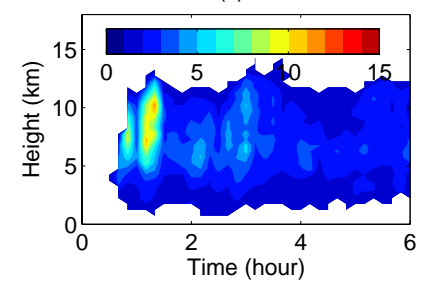

(b) DS

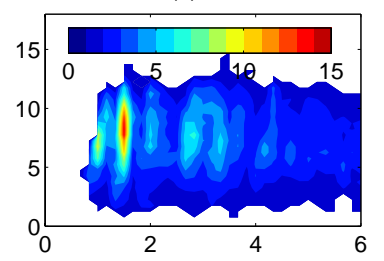

(d) CS

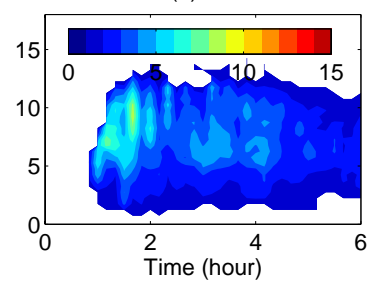

Fig. 3. Comparison of upward vertical velocity $\left(\mathrm{m} \mathrm{s}^{-1}\right)$ averaged in updraft cores $\left(\mathrm{w}>1 \mathrm{~m} \mathrm{~s}^{-1}\right.$ and $200<y<300 \mathrm{~km}$ ).

(a) DI

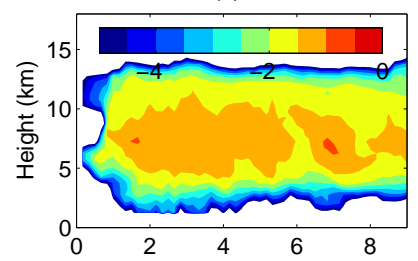

(c) $\mathrm{Cl}$

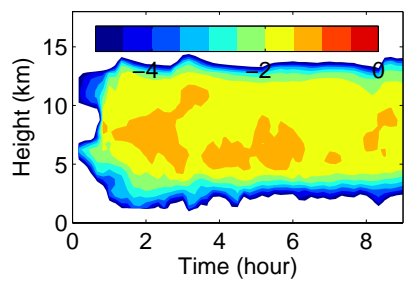

(b) DS

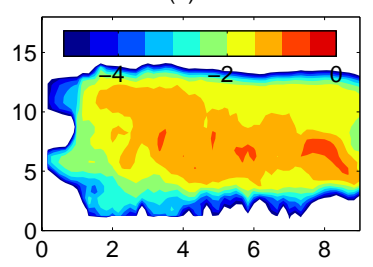

(d) CS

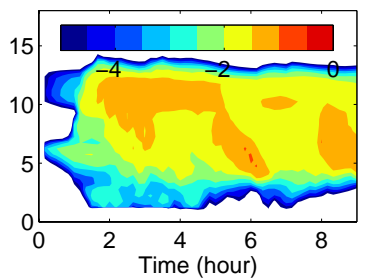

Fig. 4. Comaprison of horizontally averaged total cross section area $\left(\log 10 \mathrm{of} \mathrm{cm}^{2} \mathrm{~L}^{-1}\right)$ of ice particles in $100<y<350 \mathrm{~km}$. 
with solubility of $\mathrm{CCN}$, while the clean cases experienced decrease with solubility. The activation of $\mathrm{CCN}$ and freezing nucleation processes were closely related to solubility of CCN. In turn, riming process was affected by solubility as well as dust layers. Further investigation on microphysical processes and thermodynamics is necessary to understand the sensitivity. This case indicated the cause-effect relationships to the differences in dust layer and solubility, but note that the relationships may or may not be physically significant for other convective clouds.

This preliminary research suggests that remote sensing technology may be sensitive to differences in cloud structures caused by dust layers and solubility of CCN. Establishment of connections between cloud structures, precipitation on the ground, and radiative transfer will benefits retrievals and climate study as well as hydrology.

Acknowledgements. This work was supported by NASA (NNG04GA36G and NNX07AD43G).

Edited by: A. Mugnai

Reviewed by: one anonymous referee

\section{References}

Barkan, J., Alpert, P., Kutiel, H., and Kishcha, P.: Synoptics of dust transportation days from Africa toward Italy and central Europe, J. Geophys. Res., 110, D07208, doi:10.1029/2004JD005222, 2005.

Hashino, T. and Tripoli, G.: The Spectral Ice Habit Prediction System (SHIPS). Part I: Model description and simulation of vapor deposition process, J. Atmos. Sci., 64, 2210-2237, 2007.

Khain, A., Rosenfeld, D., and Pokrovsky, A.: Aerosol impact on the dynamics and microphysics of deep convective clouds, Q. J. R. Meteorol. Soc., 131, 2639-2663, 2005.

Pruppacher, H. R. and Klett, J. D.: Microphysics of Clouds and Precipitation, Kluwer Academic, 914 pp., 1997

Tripoli, G. J.: A nonhydrostatic mesoscale model designed to simulate scale interaction, Mon. Weather Rev., 120, 1342-1359, 1992.

Tripoli, G. J., Panegrossi, G., Mugnai, A., Dietrich, S., and Smith, E. A.: A numerical study of the Friuli, 1998 and the Genoa, 1992 floods, in: 2nd Plinius Conference on Mediterranean Storms, edited by: Mugnai, A., Guzzetti, F., and Roth, G., 127-140, 2001.

Van Den Heever, S. C., Carrio, G. G., Cotton, W. R., DeMott, P. J., and Prenni, A. J.: Impacts of nucleating aerosol on Florida storms. Part I: mesoscale simulations, J. Atmos. Sci., 63, 17521775, 2006.

Wang, Y., Zhuang, G., Sun, Y., and An, Z.: Water-soluble part of the aerosol in the dust storm season - evidence of the mixing between mineral and pollution aerosols, Atmos. Environ., 39, 7020-7029, 2005. 